\title{
Modeling Bus Dwell Time and Time Lost Serving Stop in China
}

\author{
Chao Wang, Zhirui Ye, Yuan Wang, Yueru Xu, and Wei Wang \\ Southeast University, China
}

\begin{abstract}
The primary objective of this study was to develop a quantitative approach to estimate bus dwell time and time lost serving stop, which included acceleration and deceleration time, dead time, and time for serving boarding and alighting passengers. A polynomial model incorporating kinematics of a particle was derived for estimating bus acceleration and deceleration time. In addition, descriptive statistics methods were used to analyze dead time. A case study was conducted to show the applicability of the proposed model with data collected from the seven most common types of bus stops in China. R-square and Mean Absolute Percentage Error (MAPE) were calculated to be 0.8840 and $13.20 \%$ for non-peak and 0.8387 and $13.46 \%$ for peak, indicating the method was well-validated and could be practically used in China. Further research can be conducted to investigate the effects of different weather conditions and locations on the performance of the proposed method.
\end{abstract}

Keywords: Bus dwell time, dead time, time lost serving stop, transit

\section{Introduction}

Studies have shown that bus service procedure at bus stops is of great importance to estimate capacity of a bus stop (Bian et al. 2015), and it is also a major component of bus travel time (Hawas 2013; Furth and Muller 2007; Hadas and Ceder 2010; Balasubramanian and Rao 2015). Bus service procedure plays a vital role in transit network design (Szeto et al. 2011; Wu et al. 2015; Yan et al. 2013) and transit assignment analysis (Hamdouch et al. 2011; Leurent et al. 2014). Thus, bus service time estimation is essential for bus operators and public transport planners (Ceder 2007; Li et al. 2006).

There is considerable research in the literature on the service procedure of buses at bus stops. Previous research defined the time spent serving a bus stop as the time the bus is stationary or has its doors open at the bus stop, i.e., bus dwell time. However, most research studies fail to adequately consider the time lost by the bus decelerating 
to a bus stop and then accelerating back to running speed to serve the stop (Robinson 2013). The acceleration and deceleration time is often much longer than the time lost when the doors are open at the bus stop. In addition, it has also been noted that the characteristics of a bus stop visit are not well considered. The passage of a bus through a stopping zone can be called a bus stop visit (Robinson 2013). In light of this, bus dwell time and time lost serving stop is introduced to describe the bus service procedure in this study, which is defined as the time required for serving passengers, acceleration time, and deceleration time, with the addition of dead time. According to relevant references (Robinson 2013; Cundill and Watts 1973), dead time is the time the bus is stationary at a stop but no passengers are boarding and alighting. The contributing factors for dead time are categorized as major factors (including the average delay for re-entering the car stream (Yang et al. 2009), and other additional delay (Tirachini 2013) such as boarding lost time, bus stop failure time, and traffic signal delay, and adjustment factors (including traffic volume/capacity).

In addition, there is a variety of bus stop designs that may influence bus dwell time and time lost serving stop. Based on the right-of-way, bus lanes can be divided into exclusive bus lanes (grade-separated busways and at-grade busways) and mixed traffic lanes (KFH Group 2013; Jacques and Levinson 1997). According to TCRP Report 19 (Fitzpatrick et al. 1996), bus dwell time and time lost serving stop will be affected by the layout of the bus stop. In general, the more exclusive the stop (the less interaction that a transit vehicle has with other traffic), the fewer impacts on bus dwell time and time lost serving the stop can be achieved. In terms of form, bus stops can be classified into two categories: on-line and off-line (KFH Group 2013). Compared to an on-line bus stop, there is additional time required for buses at an off-line stop to find an acceptable time gap between consecutive vehicles. It can be concluded that the form of a bus stop has an impact on bus dwell time and time lost serving stop. Moreover, based on the location of the cross-section, bus stops can be divided into two categories: median and curbside. According to the above classifications, seven types of bus stop designs are commonly observed in China (Ye et al. 2016), as illustrated in Figure 1:

Type 1: At-grade busways separated from motor vehicle lanes by traffic markings; bus stops are on-line and set on the curbside.

Type 2: No exclusive bus lane; bus stops are on-line and set on the curbside.

Type 3: At-grade busways separated from motor vehicle lanes by traffic markings; bus stops are off-line (bay-style) and set on the curbside.

Type 4: No exclusive bus lane; bus stops are off-line (bay-style) and set on the curbside.

Type 5: Grade-separated busways separated from motor vehicle lanes by separation strips; bus stops are on-line and set in the median of the cross-section.

Type 6: At-grade busways separated from motor vehicle lanes by traffic markings; bus stops are on-line and set in the median of the cross-section.

Type 7: No exclusive bus lane; bus stops are on-line and set on the curbside, and buses pull over to the curbside and occupy bicycle lanes to dwell. 
FIGURE 1.

Schematic diagram

of seven most

common bus stops

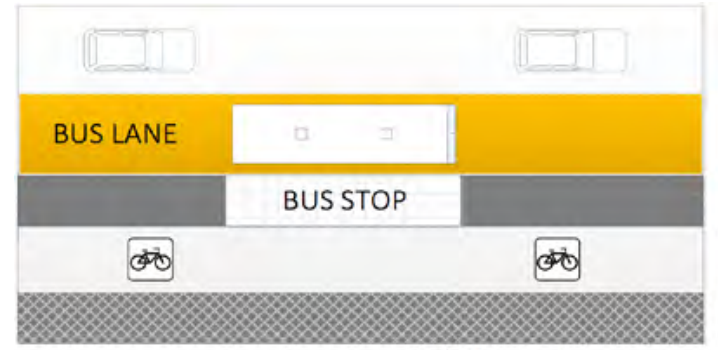

(a) Type 1

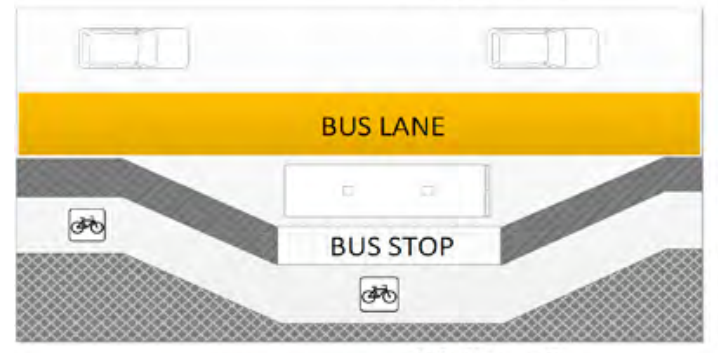

(c) Type 3

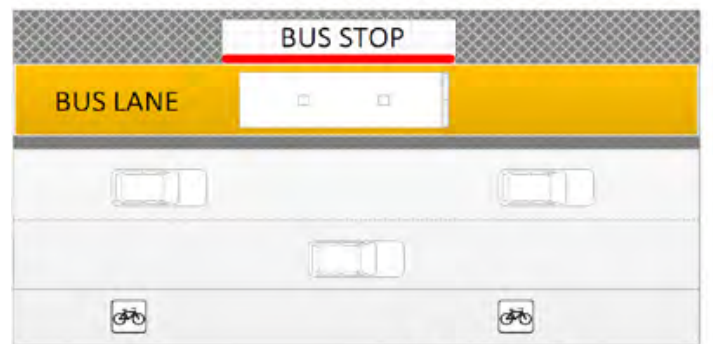

(e) Type 5

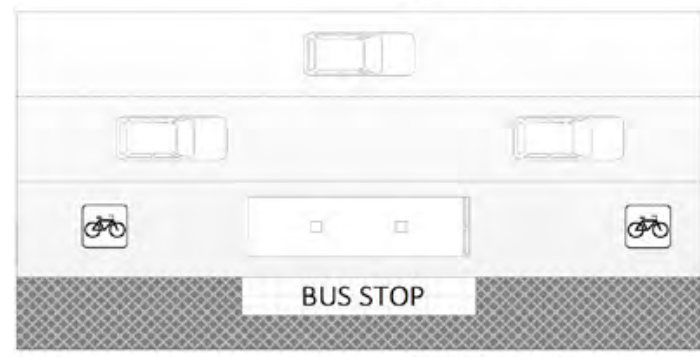

(g) Type 7

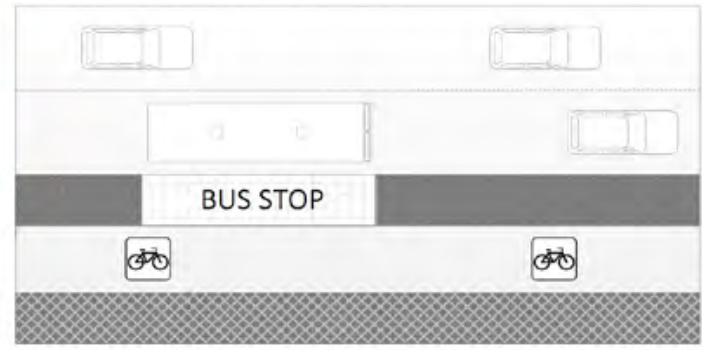

(b) Type 2

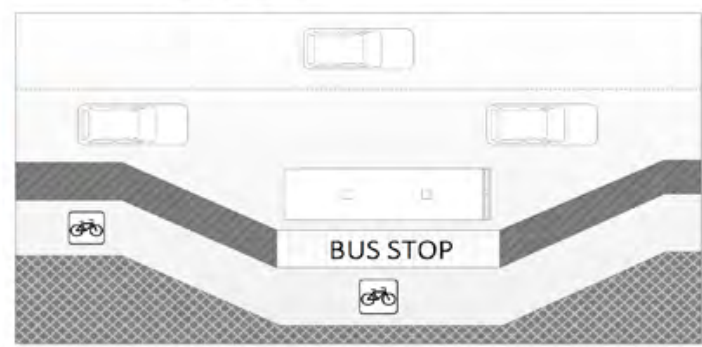

(d) Type 4

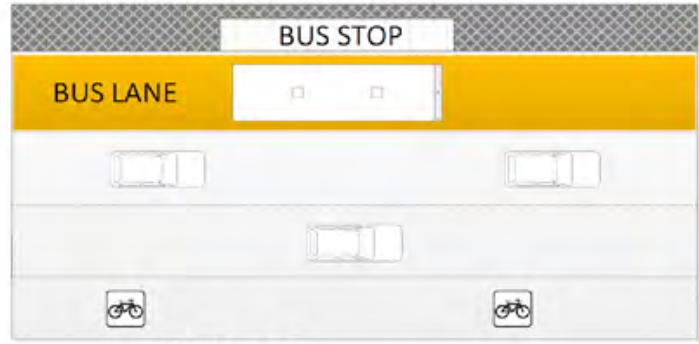

(f) Type 6
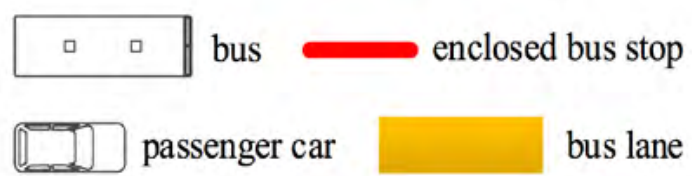

tob non-motorized vehicle

In light of these considerations, the primary objective of this study was to develop a quantitative approach to estimate bus dwell time and time lost serving stop for different types of bus stops. The method proposed in this paper can be used by transit agencies to measure the actual travel time of buses, removing the component of time lost serving the stop. The method can also be used to identify bus stops that may need redesign to reduce the time lost in arriving and departing. In addition, this study was inspired by several current bus speed improvement projects in China. Requirements gathered from the departments show that bus service time is ambiguous. Some business users wanted data about time spent with doors open, and others wanted the time lost serving stop. This study can meet both requirements. 


\section{Literature Review}

There are two processes going on during bus service at stops (Fernandez 2010). One is the time spent for serving boarding and alighting passengers, known as bus dwell time. The earliest research on dwell time at a bus stop was given by Levinson (1983), who formulated the bus dwell time as a function of two primary contributing factors, number of alighting and boarding passengers, by using the linear regression approach. Since then, more research approaches were introduced to take into account several secondary factors that might affect the effectiveness of bus dwell time estimation. For example, Guenthner and Hamat (1988) associated bus dwell time with fare collection system. In Lin and Wilson's study (1992), a functional form that combined with the crowding effect was developed. In addition, several studies found that the dwell time also relied on vehicle occupancy and bus floor types (Levine and Torng 1994; Fernandez et al. 1995).

The other part of the service procedure is the time taken for buses to enter and leave the service area, known as time lost serving stop. The literature shows that little research has been done on that component of time lost decelerating and accelerating to a bus stop and other bus delay at a stop. Research by Jaiswal et al. (2010) suggested that the bus stop design could affect time spent at a stop. According to Robinson (2013), the time lost arriving at (i.e., decelerating) and departing from (i.e., accelerating) a bus stop was typically $11.6 \mathrm{~s}$ in London.

Previous studies on dwell time and time lost serving stop had used limited manuallycollected data sets to relate dwell time and time lost serving stop to several factors, with separate equations estimated for different operating characteristics likely to have an impact on dwell time and time lost serving stop (Dueker et al. 2004). However, the cost of collecting data manually limited the number of observations in these data sets to a handful of operators, stops, and so on (Milkovits 2008).

In recent years, advanced technologies such as automatic transit information systems provide real-time information that can assist transit agencies and researchers in collecting data of better quality and monitoring the operation of a transit system ( $\mathrm{Li}$ et al. 2006). For instance, with the widespread application of automatic data collecting systems including automatic passenger counting (APC) and automatic vehicle location $(\mathrm{AVL})$ systems, transit agencies and researchers are able to analyze a plethora of data by using an archived database (Tirachini 2013; Dueker et al. 2004). In addition, several computer simulation models have been applied in bus operation analysis at stops. The TRAF-NETSIM program, i.e., CORSIM, deals with time spent at a stop by simply depending on mean values specified by users and embedded statistical distributions rather than loading and unloading demand (FHWA 2003). VISSIM is another prevalent simulation model to analyze bus dwell time and time lost serving stop, which is estimated by two methods including dwell time distributions and advanced passenger models (PTV Group 2005).

However, an automatic data collection system cannot provide all of the required data for calculating bus dwell time and time lost serving stop. Thus, this study involved the 
following factors based on automatically- and manually-collected data. The features of a bus stop visit can be measured by automatic data collecting systems, such as the number of passengers boarding and alighting, stop entry/exit, and zero speed start/ end. As for the additional delay for buses and layout of bus stops (Gu et al. 2011; Meng and Qu 2013), however, they cannot be clearly measured by APC and AVL systems. For instance, a passenger who is far away from the alighting and boarding area may take longer to board a bus than a passenger near the area. This process can be observed by manually collecting data instead of automatically collecting data, because the latter merely records the bus delay and does not help us learn what happened in the process.

\section{Methodology}

\section{Contributing Factors to Bus Dwell Time and Time Lost Serving Stop}

Many factors can affect bus dwell time and time lost serving stop; among them the number of boarding or/and alighting passengers is the most significant contributing factor (Tirachini 2013; Milkovits 2008). A field investigation was conducted to collect bus dwell time and time lost serving stop and the number of boarding and alighting passengers associated with buses at the seven most common bus stop designs in China (Figure 2). Data were collected from 885 stopped buses. It should be noted that the bus stops in this study were selected randomly, and all pilot studies have been conducted with the findings, on the assumption that these seven bus stops can well represent the results for their relevant bus stop categories.

FIGURE 2.

Dwell time and time lost serving stop vs. number of boarding and alighting

passengers

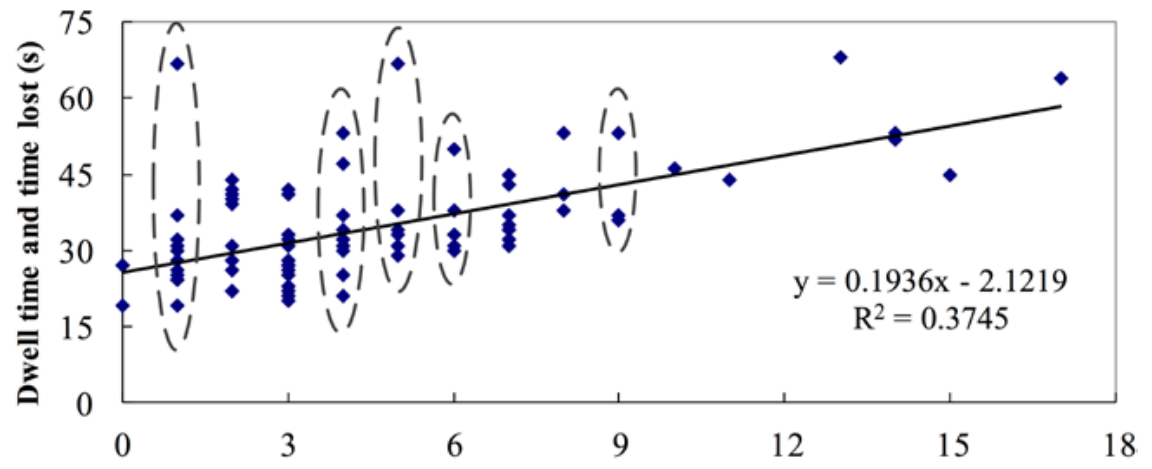

According to the types of bus stop design, these 885 samples enabled us to establish a respective linear relationship between the bus dwell time and time lost serving stop and the number of alighting and boarding passengers by the linear regression approach that had been widely used in existing studies (Meng and Qu 2013). Unfortunately, the linear relationship did not hold due to the relevant low $R$-square value $\left(R^{2}=0.3912\right.$, on average). Figure 2 presents the linear regression results at one of the bus stops selected for this study-Public Transport Corporation bus stop. Interestingly, as can be seen in Figure 2, these data scattered on a 2-dimensional plane, in which the abscissa axis denoted the number of boarding and alighting passengers and the ordinate axis denoted the bus dwell time and time lost serving stop, apparently indicating bus dwell time and time 
lost serving stop differed greatly among the same number of passengers (i.e., the dotted line circles in Figure 2). For instance, bus dwell time and time lost serving stop ranged from $21 \mathrm{~s}$ to $53 \mathrm{~s}$ when the number of passengers was equal to 4. As analyzed above, it is problematic to estimate bus dwell time and time lost serving stop merely by relying on the number of boarding and alighting passengers, and it is necessary to take into account other factors such as dead time and acceleration and deceleration time.

\section{Bus Acceleration and Deceleration Time}

As shown in Figure 3, a bus stop includes three areas: bus entry area, alighting and boarding areas for passengers, and bus exit area. These entry and exit areas allow a bus to safely enter the bus stop from the shoulder lane and leave the bus stop to merge into traffic on the shoulder lane. According to the Transit Capacity and Quality of Service Manual (TCQSM) (KFH Group 2013), it takes time for a bus to slow from its running speed to serve a bus stop, and additional time to accelerate back to its running speed after serving the stop at a comfortable deceleration rate of $1.2 \mathrm{~m} / \mathrm{s}^{2}$ and acceleration rate of $1.0 \mathrm{~m} / \mathrm{s}^{2}$, compared to proceeding past the bus stop without stopping.

FIGURE 3.

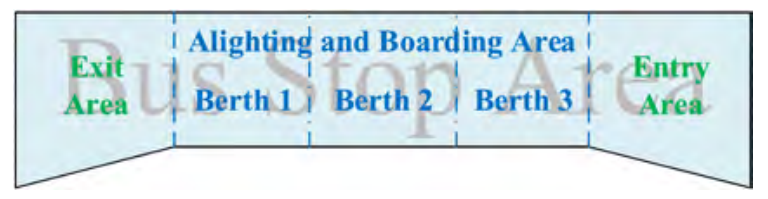

Acceleration and deceleration distances and time, together with the initial and final speeds during acceleration and deceleration processes, are the key information for modeling acceleration and deceleration of vehicles. A polynomial model incorporating kinematics of a particle is derived for estimating the bus acceleration process in the exit area and deceleration process in the entry area.

\section{Acceleration Process in Exit Area}

When a bus begins to accelerate away from a stop immediately after it last closes its doors, the acceleration distance to accelerate back to its running speed at a constant acceleration is:

$$
S_{1}=\left(a_{a c} / 2\right) \times\left(v / a_{a c}\right)^{2}=v^{2} /\left(2 \times a_{a c}\right)
$$

where $S_{1}$ is the acceleration distance, $a_{a c}$ represents the acceleration rate $\left(1.0 \mathrm{~m} / \mathrm{s}^{2}\right)$, and $v$ is the bus running speed. If the length of the exit area is too long, so that the bus is still in this area when it accelerates back to the running speed, the remaining distance in the exit area $\Delta S_{a c}$ can be expressed as:

$$
\Delta S_{a c}=S_{a c}-S_{1}=S_{a c}-v^{2} /\left(2 \times a_{a c}\right)
$$

where $S_{a c}$ is length of the exit area. Thus, the acceleration time of a bus $t_{a c}$ is as follows: 


$$
t_{a c}= \begin{cases}v / a_{a c}, & \Delta S_{a c} \leq 0 \\ v / a_{a c}+\Delta S_{a c} / v=S_{a c} / v+v /\left(2 \times a_{a c}\right), & \Delta S_{a c}>0\end{cases}
$$

\section{Deceleration Process in Entry Area}

Similar to the acceleration process in the exit area, the deceleration distance of a bus, which slows from its running speed to serve a bus stop at a constant deceleration, is:

$$
S_{2}=\left(a_{d e} / 2\right) \times\left(v / a_{d e}\right)^{2}=v^{2} /\left(2 \times a_{d e}\right)
$$

where $S_{2}$ is the deceleration distance and $a_{d e}$ represents the deceleration rate $\left(1.2 \mathrm{~m} / \mathrm{s}^{2}\right)$.

If the length of the entry area is too long, the remaining distance in the entry area $\Delta S_{d e}$ can be expressed as:

$$
\Delta S_{d e}=S_{d e}-S_{2}=S_{d e}-v^{2} /\left(2 \times a_{d e}\right)
$$

where $S_{d e}$ is length of the entry area. Thus, the deceleration time of a bus $t_{d e}$ is as follows:

$$
t_{d e}= \begin{cases}v / a_{d e}, & \Delta S_{d e} \leq 0 \\ v / a_{d e}+\Delta S_{d e} / v=S_{d e} / v+v /\left(2 \times a_{d e}\right), & \Delta S_{d e}>0\end{cases}
$$

The acceleration and deceleration time of a bus $t_{a c-d e}$ in the exit and entry areas can be summarized as follows:

$$
t_{a c-d e}=t_{a c}+t_{d e}= \begin{cases}v / a_{a c}+v / a_{d e}, & \Delta S_{a c} \leq 0, \Delta S_{d e} \leq 0 \\ v / a_{a c}+S_{d e} / v+v /\left(2 \times a_{d e}\right), & \Delta S_{a c} \leq 0, \Delta S_{d e}>0 \\ S_{a c} / v+v /\left(2 \times a_{a c}\right)+v / a_{d e}, & \Delta S_{a c}>0, \Delta S_{d e} \leq 0 \\ S_{a c} / v+S_{d e} / v+v /\left(2 \times a_{a c}\right)+v /\left(2 \times a_{d e}\right), & \Delta S_{a c}>0, \Delta S_{d e}>0\end{cases}
$$

\section{Serving Boarding and Alighting Passengers}

Bus dwell time and time lost serving stop may be affected by boarding demand (e.g., in the PM peak period when relatively empty buses arrive at a heavily-used stop), by alighting demand (e.g., in the AM peak period at the same location), or by total interchanging passenger demand (e.g., at a major transfer point). In all cases, the time for serving boarding and alighting passengers is proportional to the boarding and/or alighting volumes and the amount of time required to serve each passenger (KFH Group 2013).

Several main factors influence the time for serving passengers. The number of people passing through the highest-volume door is a key factor in how long it will take for all passengers to be served. The proportion of alighting to boarding passengers through the busiest door also affects how long it takes all passenger movements to occur. The average time to pay a fare is a major influence on the time required to serve each 
boarding passenger. Some types of fare payment procedures allow passengers to board through more than one door at busy stops, thus allowing all to be served more quickly. Having to ascend or descend steps while getting on and off the bus increases the amount of time required to serve each passenger. In addition, when standees are present on a bus, it takes more time for boarding passengers to clear the farebox area, as other passengers must move to the back of the bus (KFH Group 2013).

In this study, the time for serving boarding and alighting passengers $t_{s}$ is the time required to serve passengers at the busiest door plus the time required to open and close the doors. A value of $2-5 \mathrm{~s}$ for door opening and closing is reasonable for normal operations (Levinson 1983; Meng and Qu 2013).

$$
t_{s}= \begin{cases}P_{u p} \times t_{u p}+P_{\text {down }} \times t_{\text {down }}+t_{o c}, & N_{u p}+N_{\text {down }}=1 \\ \max \left\{\left(P_{u p} \times t_{u p}\right) / N_{u p},\left(P_{\text {down }} \times t_{\text {down }}\right) / N_{\text {down }}\right\}+t_{o c}, & N_{u p}+N_{\text {down }} \geq 2\end{cases}
$$

where $P_{\text {up }}$ is number of boarding passengers, $P_{\text {down }}$ denotes number of alighting passengers, $N_{u p}$ is number of doors for boarding, $N_{\text {down }}$ denotes number of doors for alighting, and $t_{o c}$ is door opening and closing time. According to TCQSM (KFH Group 2013), the service time for each passenger $t_{u p}$ and $t_{\text {down }}$ is defined in Table 1. Table 1 can be used to estimate the time for typical situations where only one direction of passengers uses a door at a time and all passengers board through a single door. When passengers may board through multiple doors, Table 2 can be used instead to estimate the time. According to the field investigations described above, these data from TCQSM can be reflective of Chinese conditions.

TABLE 1.

Passenger Service Time with Single-channel Passenger Movement

\begin{tabular}{|l|l|c|}
\hline \multicolumn{2}{|c|}{ Situation } & Service Time (sec per passenger) \\
\hline \multirow{4}{*}{ Boarding } & Pre-payment & 2.5 \\
\cline { 2 - 3 } & Single ticket or token & 3.5 \\
\cline { 2 - 3 } & Exact change & 4.0 \\
\cline { 2 - 3 } & Swipe or dip card & 4.2 \\
\cline { 2 - 3 } & Smart card & 3.5 \\
\hline \multirow{3}{*}{ Alighting } & Front door & 3.3 \\
\cline { 2 - 3 } & Rear door & 2.1 \\
\hline
\end{tabular}

Source: Transit Capacity and Quality of Service Manual (KFH Group 2013)

TABLE 2.

Passenger Service Time with Multiple-channel Passenger Movement

\begin{tabular}{|c|c|c|c|}
\hline \multirow{2}{*}{$\begin{array}{c}\text { Number } \\
\text { of Doors }\end{array}$} & \multicolumn{3}{|c|}{ Service Time (sec per passenger) } \\
\cline { 2 - 4 } & Boarding Time & Front Door Alighting Time & Rear Door Alighting Time \\
\hline 1 & 2.5 & 3.3 & 2.1 \\
\hline 2 & 1.5 & 1.8 & 1.2 \\
\hline 3 & 1.1 & 1.5 & 0.9 \\
\hline 4 & 0.9 & 1.1 & 0.7 \\
\hline 6 & 0.6 & 0.7 & 0.5 \\
\hline
\end{tabular}

Source: Transit Capacity and Quality of Service Manual (KFH Group 2013) 
It is noted that when there are passengers standing in the bus, the boarding time will increase by $20 \%$. For low-floor buses, the boarding time is reduced by $20 \%$, the front door alighting time decreases by $15 \%$, and the rear door alighting time is shortened by 25\% (KFH Group 2013).

\section{Bus Dead Time at Bus Stop}

Bus dead time at a bus stop consists of average delay for re-entering the traffic stream and other additional delay such as boarding lost time, bus stop failure time, and traffic signal delay. Average delay for re-entering the traffic stream is a function of the capacity and the degree of saturation in the vicinity of a bus stop (Yang et al. 2009; HCM 2000). It is important to note that, for grade-separated busways (Type 5) and at-grade busways (Types 1, 3 and 6), average delay for re-entering the traffic stream is equal to 0 . That is because the buses in grade-separated and at-grade busways cannot be disturbed by other non-bus vehicles. The analytical model used to estimate average delay assumes that the demand is less than capacity for the period of analysis. According to the Highway Capacity Manual (2000), if the degree of saturation is greater than about 0.9, average delay for re-entering the traffic stream is significantly affected by the length of the analysis period. In most cases, the recommended analysis period is 15 minutes.

$$
t_{a d}=3600 / C+900 \times T \times\left(V / C-1+\sqrt{(V / C-1)^{2}+(3600 / C) \times(V / C) /(450 \times T)}\right)
$$

where $t_{a d}$ is average delay for re-entering the car stream, and $T$ represents the analysis time period, $T=0.25$ for a 15 -minute period.

In addition to average delay for re-entering the traffic stream, there are several sources of delay that influence bus dead time at bus stops:

- Boarding lost time $t_{b}$ - This is the time spent waiting for passengers to walk to the bus door(s) from their waiting position at the stop. When passengers wait at bus stops with multiple loading areas, such as high-volume stations served by multiple routes, they do not know in advance at which loading area the bus will stop when it arrives. According to a relevant reference (Jaiswal 2010) and our observations, passengers tend to concentrate within half a loading area length of the front of the second loading area-the point where the door of the second bus would be located. Once this optimal area becomes too crowded, passengers first spill toward the front loading area and later toward the rear loading area. When a bus arrives, there is typically a delay from when the bus doors open and when the first passenger arrives to board the bus. It depends on where the passengers were waiting relative to where the bus stopped, how quickly they could determine where the bus would stop, and how crowded the platform area was.

- Bus stop failure time $t_{f}$ - A bus arrives at a stop to find all loading areas occupied, forcing it to wait until other buses leave the stop. In addition, when a bus is ready to depart from a stop, it also has to wait if it is blocked by other buses at the stop. These are examples of bus stop failure. In this case, the bus will have a delay (i.e., 
bus stop failure time) waiting for all of the buses at the stop to finish serving their passengers.

- Traffic signal delay $t_{s d}$ - This is the time spent waiting for a green light after passenger flow has been completed. A traffic signal located in the vicinity of a bus stop and its loading areas will serve to meter the number of buses that can enter or exit the stop. For instance, at a far-side stop of a signalized intersection, buses can enter the stop only during the portion of the hour when the signal is green for the street on which the stop is located. The shorter the green time provided to the street, the lower the capacity and the longer a bus is likely to wait if it has to wait for the traffic signal to turn green again.

\section{Bus Stop Dwell Time and Time Lost Serving Stop}

The bus stop dwell time and time lost serving stop $T_{d l}$ is based on the bus acceleration and deceleration time, time for serving boarding and alighting passengers, and bus dead time at bus stop. The final model is given in the following equation:

$$
T_{d l}=t_{a c}+t_{d e}+t_{s}+t_{a d}+t_{b}+t_{f}+t_{s d}
$$

To intuitively describe the model, the equation for bus dwell time and time lost serving stop is represented by an expression tree in Figure 4. As shown in Figure 4, the nodes consist of variables, constants, and arithmetic symbols, such as,,$+- \times$, and $\div$.

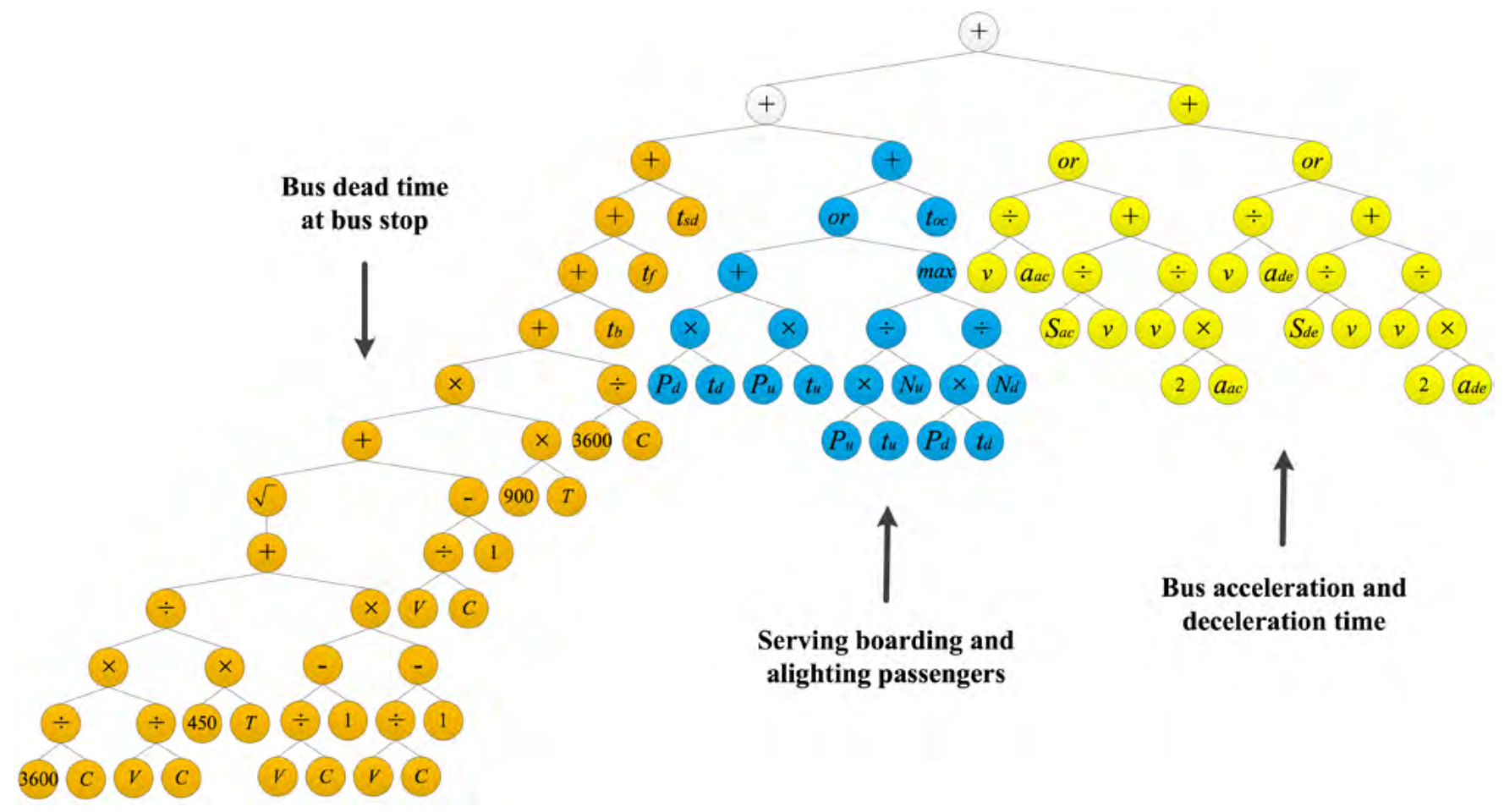

FIGURE 4. Expression tree for bus dwell time and time lost serving stop 


\section{Data Collection and Analysis}

In this study, data were collected at seven different types of bus stops in the cities of Nanjing, Changzhou, and Guangzhou, China. The data were collected under good weather conditions between May 19 and June 15, 2014, to exclude potential influence of adverse weather. In addition, there was no curb parking around the stops.

Three video cameras were used at each stop to record traffic data, with one set up on a high location and one each set up in front of and behind the bus stop. The recorded videos were reviewed by several trained graduate students to obtain traffic volume and bus average speed near the bus stop. The site and traffic flow characteristics of the bus stops are shown in Table 3.

TABLE 3.

Site and Traffic Flow Characteristics of Bus Stops

\begin{tabular}{|c|c|c|c|c|c|c|c|c|}
\hline No. & Bus Stop & Type & $\mathbf{B S L}^{a}$ & $\mathrm{TC}^{b}$ & $\mathbf{S S}^{c}$ & $\mathbf{V}^{d}$ & $\mathbf{C}^{e}$ & $\mathbf{B S}^{f}$ \\
\hline 1 & \multirow{2}{*}{ Gulou North } & \multirow{2}{*}{ Type 1} & \multirow{2}{*}{47.5} & Peak & 67 & 2677 & 4500 & 21.4 \\
\hline 2 & & & & Non-peak & 47 & 1723 & 4500 & 24.4 \\
\hline 3 & \multirow{2}{*}{ Beiji Huitang } & \multirow{2}{*}{ Type 2} & \multirow{2}{*}{20.0} & Peak & 113 & 3017 & 3900 & 18.9 \\
\hline 4 & & & & Non-peak & 108 & 2155 & 3900 & 22.5 \\
\hline 5 & \multirow{2}{*}{$\begin{array}{l}\text { Public Transport } \\
\text { Corporation }\end{array}$} & \multirow{2}{*}{ Type 3} & \multirow{2}{*}{72.3} & Peak & 96 & 3378 & 4500 & 23.7 \\
\hline 6 & & & & Non-peak & 101 & 2286 & 4500 & 26.0 \\
\hline 7 & \multirow{2}{*}{ Xuanwuhu Park } & \multirow{2}{*}{ Type 4} & \multirow{2}{*}{78.6} & Peak & 40 & 3850 & 4500 & 22.6 \\
\hline 8 & & & & Non-peak & 56 & 3054 & 4500 & 25.7 \\
\hline 9 & \multirow{2}{*}{ Renmin Park } & \multirow{2}{*}{ Type 5} & \multirow{2}{*}{38.1} & Peak & 34 & 2398 & 4000 & 19.6 \\
\hline 10 & & & & Non-peak & 40 & 1755 & 4000 & 22.9 \\
\hline 11 & \multirow{2}{*}{ Gangding } & \multirow{2}{*}{ Type 6} & \multirow{2}{*}{33.5} & Peak & 51 & 2848 & 4500 & 21.9 \\
\hline 12 & & & & Non-peak & 52 & 2205 & 4500 & 26.8 \\
\hline 13 & \multirow{2}{*}{ Danfeng Street } & \multirow{2}{*}{ Type 7} & \multirow{2}{*}{17.4} & Peak & 39 & 2078 & 3000 & 15.9 \\
\hline 14 & & & & Non-peak & 41 & 1386 & 3000 & 20.2 \\
\hline
\end{tabular}

a: Length of bus stop area $(m)$

$b$ : Traffic condition (peak period or non-peak period)

$c$ : Sample size of buses (veh)

$d$ : Traffic flow rate (veh/h)

e: Capacity (veh/h)

$f:$ Bus average speed near the bus stop $(\mathrm{km} / \mathrm{h})$

In Table 3, BSL represents the length of the bus stop area, which consists of the bus entry area, alighting and boarding areas of passengers, and the bus exit area. The length of the bus stop area can be measured by tapeline in the field investigations. SS represents the sample size of buses. The duration of data collection for each bus stop was two hours for peak and two hours for non-peak. BS represents the bus average speed near the stop, which is the running speed before and after the bus stop. In general, a stopped bus will slow from its running speed about $50 \mathrm{~m}$ before the bus stop and will accelerate back to its running speed about $30 \mathrm{~m}$ after the stop. In this study, bus average speed near the stop was calculated by measuring the elapsed time to travel a specific distance (typically about $4.5 \mathrm{~m}$ ) in the video. The VideoStudio application 
was used to process the video files in a frame-by-frame way so the observer could view videos at 25 frames per second.

- Boarding lost time $t_{b}$ - According to the field investigations described above, the amount of boarding lost time was found to vary by different types of bus stop designs, with median values ranging from 2.9-4.1s and interquartile range values ranging from $0.4-0.9 \mathrm{~s}$. The distributions of boarding lost time at the seven common bus stops are shown in Figure 5. From Figure 5, a fairly concentrated distribution can be observed for each type of bus stop, with a range of $0.7 \mathrm{~s}$ on average between upper quartile and lower quartile. Thus, we use median values as boarding lost time for each bus stop.

FIGURE 5.

Distributions of boarding lost time at seven common bus stops

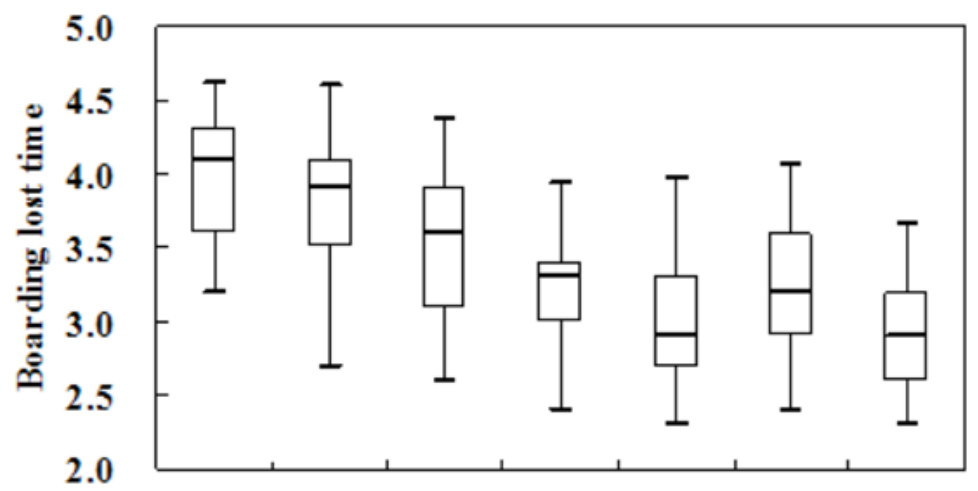

Type 1 Type 2 Type 3 Type 4 Type 5 Type 6 Type 7

\section{Bus stop}

- Bus stop failure time $t_{f}$ - According to the field investigations, the amount of bus stop failure time was also found to vary by different types of bus stops, with median values ranging from 4.9-6.4s and interquartile range values ranging from 0.5-0.9s. The distributions of bus stop failure time at the seven common bus stops are shown in Figure 6. Similar to Figure 5, it also has a fairly concentrated distribution for each type of bus stop, with a range of $0.7 \mathrm{~s}$ on average between upper quartile and lower quartile. Thus, the median values can be used as bus stop failure time.

FIGURE 6.

Distributions of bus stop failure time at seven common bus stops

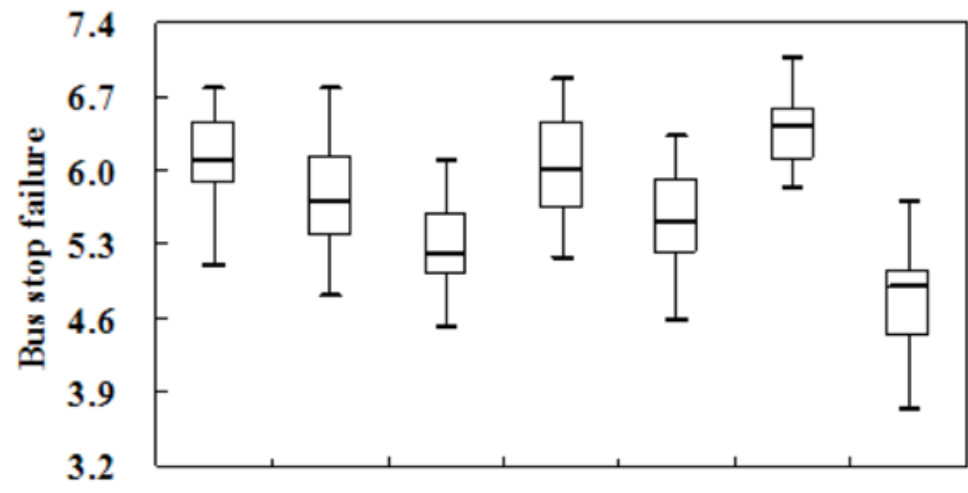

Type 1 Type 2 Type 3 Type 4 Type 5 Type 6 Type 7

Bus stop 
- Traffic signal delay $t_{s d}$ - According to the field investigations, the amount of traffic signal delay was found only at bus stops where a traffic signal is nearby, with median values ranging from 14.5-21.1s and interquartile range values ranging from 12.1-12.8s. When traffic signal delays at bus stops are frequent enough, they should be added into the bus dwell time and time lost serving stop. However, in this study, traffic signal delay was rare. According to TCQSM (KFH Group 2013), in this case, the impact of traffic signal delay was accounted for by dwell time variability instead of added into the bus dwell time and time lost serving stop.

\section{Model Validation}

\section{Comparison of Results}

Frequency histograms and cumulative distribution curves for bus dwell time and time lost serving stop during peak and non-peak periods at the seven types of bus stops are presented in Figure 7. From Figures $7(a)$ and $7(b)$, cumulative curves for calculated bus dwell time and time lost serving stop at Type 2 and Type 7 bus stops were invariably to the left of the curves for other types of bus stops during peak and non-peak periods. This indicated that dwell time and time lost serving stop at Type 2 and Type 7 were shorter than at other types, owing to the short distance of bus stop areas. By contrast, the cumulative curve for Type 4 was invariably to the right of the curves for other types of bus stops during peak and non-peak periods. For other types of bus stops, it could be observed that peak and non-peak periods had obvious influences on calculated bus dwell time and time lost serving stop. On the other hand, from Figures $7(\mathrm{a})$ and 7 (c) and Figures 7 (b) and $7(d)$, it could be shown that frequency histograms and cumulative distribution curves for calculated values closely followed those observed values during both peak and non-peak periods.

FIGURE 7.

Comparison of calculated and observed bus dwell time and time lost serving stop between peak and non-peak periods

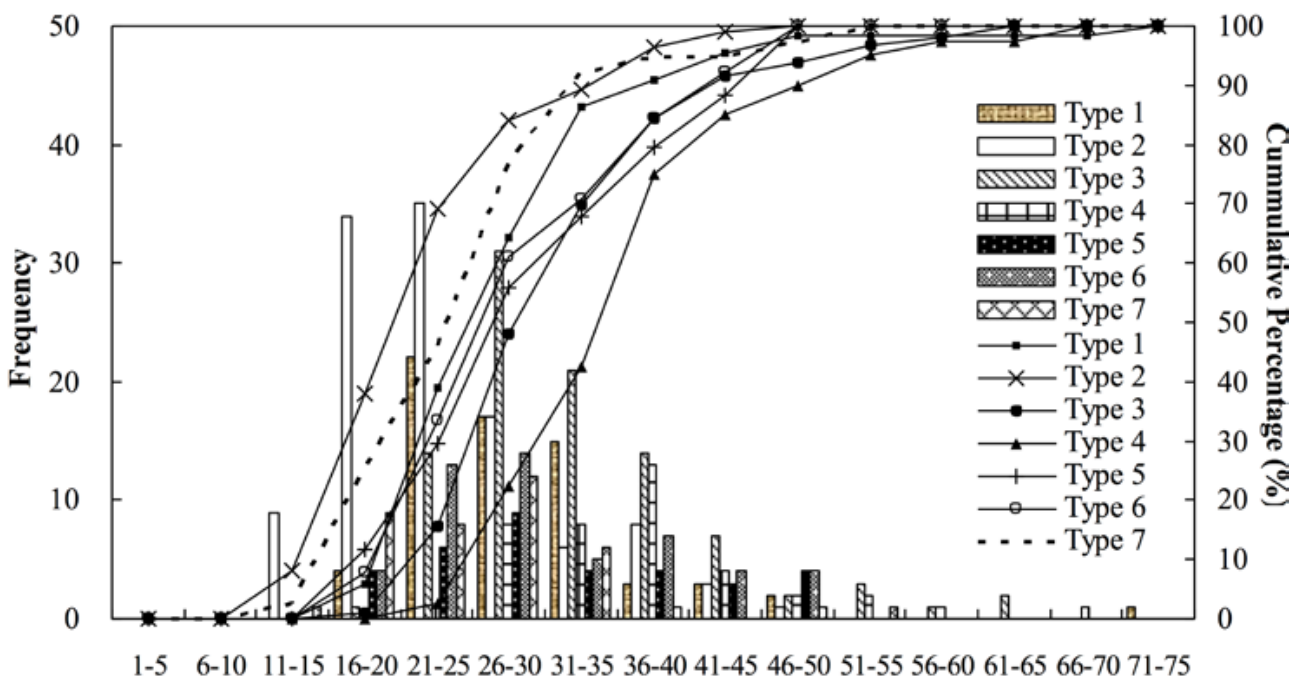

(a) Calculated bus dwell time and time lost serving stop (peak period) 
FIGURE 7. (cont'd)

Comparison of calculated and observed bus dwell time and time lost serving stop between peak and non-peak periods

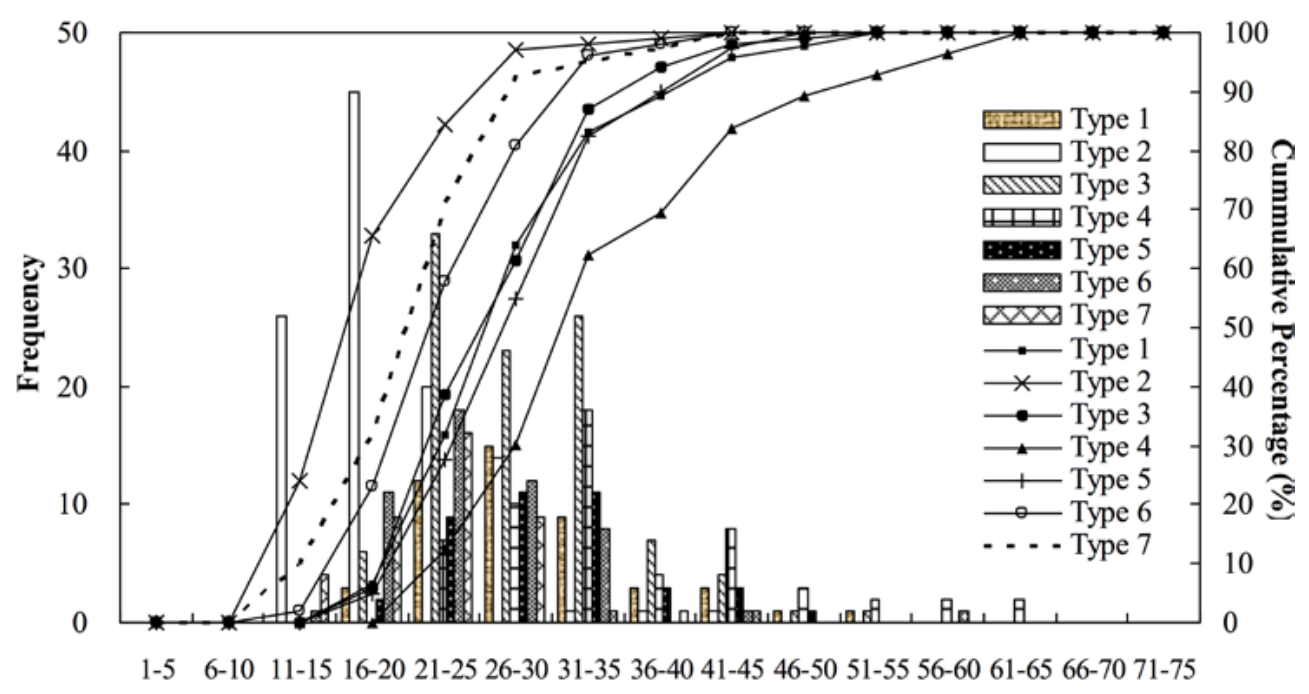

(b) Calculated bus dwell time and time lost serving stop (non-peak period)

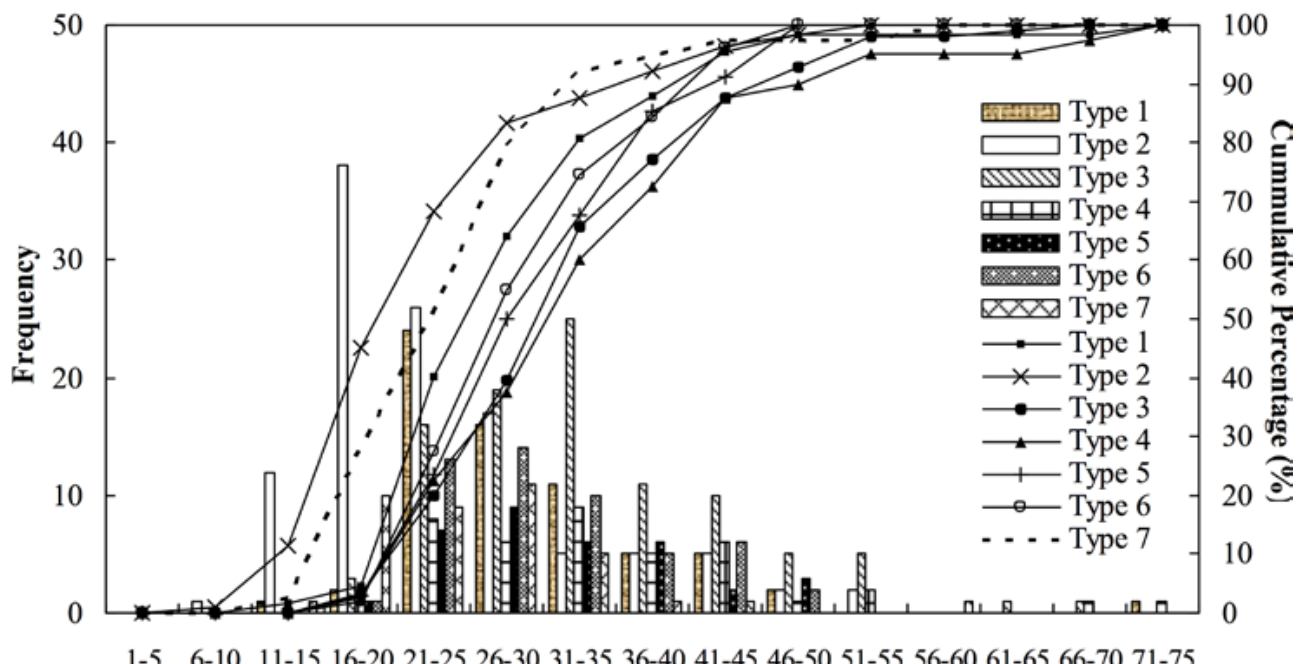

(c) Observed bus dwell time and time lost serving stop (peak period) 
FIGURE 7. (cont'd)

Comparison of calculated and observed bus dwell time and time lost serving stop between peak and non-peak periods

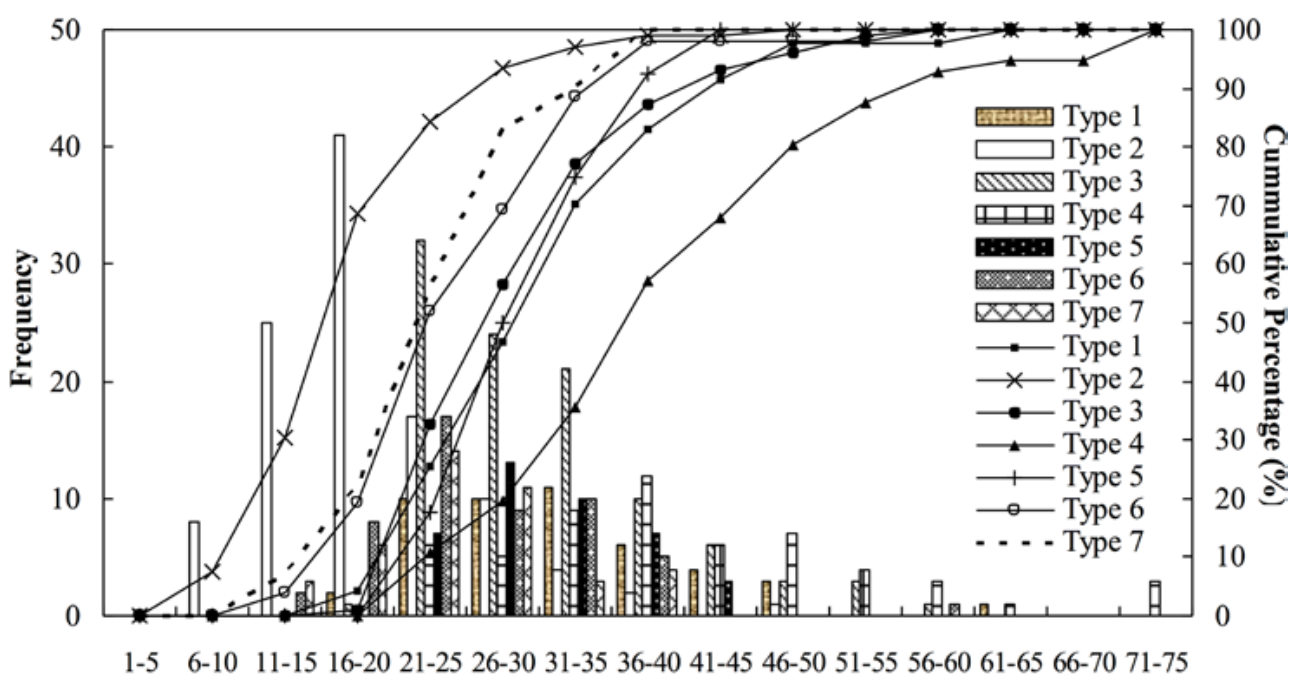

(d) Observed bus dwell time and time lost serving stop (non-peak period)

In addition, we distinguished between passengers by age: adults (including children) and older adults (age 65+), which allowed us to estimate the different boarding and alighting times of each passenger group. Among all passengers, the percentages of adults and older adults are $82 \%$ and $18 \%$, respectively. The boarding time for adults and older adults had, on average, a difference of 1.01 seconds per passenger, indicating that older people are slower to board buses. The difference due to age also is observed in alighting: whereas each adult takes, on average, 1.52 seconds to alight, each older adults takes 2.68 seconds. Thus, older adult passengers are slower to board and alight than younger travelers.

The Mean Absolute Percentage Error (MAPE) was used to measure the differences between the observed and calculated bus dwell time and time lost serving stop. MAPE has no requirement for sample size and shows an obvious advantage in evaluating discrete data. The value of MAPE in this study can be calculated using the following equation:

$$
\text { MAPE }=\frac{1}{N} \sum_{i=1}^{N}\left|\frac{T_{d w e l l}^{i}-t_{\text {dwell }}^{i}}{t_{\text {dwell }}^{i}}\right|
$$

where $N$ denotes the sample size, and $T_{d w e l l}^{i}$ and $t_{d w e l l}^{i}$ are calculated and observed bus dwell time and time lost serving stop, respectively.

Table 4 presents several measures of effectiveness, including MAPE and R-square values for estimating bus dwell time and time lost serving stop at different bus stops.

According to the results of R-square and MAPE, the bus stops having exclusive bus lanes (Types 1, 3, 5, and 6) had better performance than those having mixed traffic lanes (Types 2, 4, and 7). The buses in mixed traffic lanes may be disturbed by other motor vehicles and non-motor vehicles, causing variability for estimating bus dwell time and time lost serving stop. Thus, the right-of-way in the vicinity of a bus stop had obvious influences on the performance of the results. The peak/non-peak period, however, 
was not a key factor to determine the performance of bus dwell time and time lost estimation. For instance, at the Public Transport Corporation bus stop (Type 3), the value of R-square (0.8331) and MAPE (13.23\%) in the non-peak period were better than those ( 0.8294 and $14.39 \%$, respectively) in the peak period. However, at Beiji Huitang bus stop (Type 2), the results were contrary to those at the Public Transport Corporation stop.

TABLE 4.

Summary Statistics of Bus Dwell Time and Time Lost Serving Stop at Different Types of Bus Stops

\begin{tabular}{|c|c|c|c|c|c|c|}
\hline No. & Bus Stop & Type & State & $\begin{array}{l}\text { Sample } \\
\text { Size }\end{array}$ & $\begin{array}{l}\text { R-square } \\
\text { Value }\end{array}$ & MAPE \\
\hline 1 & \multirow{2}{*}{$\begin{array}{l}\text { Gulou } \\
\text { North }\end{array}$} & \multirow{2}{*}{ Type 1} & Peak & 67 & 0.8412 & $12.53 \%$ \\
\hline 2 & & & Non-peak & 47 & 0.8341 & $12.01 \%$ \\
\hline 3 & \multirow{2}{*}{$\begin{array}{l}\text { Beiji } \\
\text { Huitang }\end{array}$} & \multirow{2}{*}{ Type 2} & Peak & 113 & 0.8038 & $13.42 \%$ \\
\hline 4 & & & Non-peak & 108 & 0.7982 & $14.03 \%$ \\
\hline 5 & \multirow{2}{*}{$\begin{array}{l}\text { Public } \\
\text { Transport } \\
\text { Corporation }\end{array}$} & \multirow{2}{*}{ Type 3} & Peak & 96 & 0.8294 & $14.39 \%$ \\
\hline 6 & & & Non-peak & 101 & 0.8331 & $13.23 \%$ \\
\hline 7 & \multirow{2}{*}{$\begin{array}{l}\text { Xuanwuhu } \\
\text { Park }\end{array}$} & \multirow{2}{*}{ Type 4} & Peak & 40 & 0.8142 & $13.99 \%$ \\
\hline 8 & & & Non-peak & 56 & 0.8066 & $13.15 \%$ \\
\hline 9 & \multirow{2}{*}{$\begin{array}{l}\text { Renmin } \\
\text { Park }\end{array}$} & \multirow{2}{*}{ Type 5} & Peak & 34 & 0.8744 & $10.02 \%$ \\
\hline 10 & & & Non-peak & 40 & 0.8873 & $9.54 \%$ \\
\hline 11 & \multirow{2}{*}{ Gangding } & \multirow{2}{*}{ Type 6} & Peak & 51 & 0.8534 & $12.09 \%$ \\
\hline 12 & & & Non-peak & 52 & 0.8691 & $13.05 \%$ \\
\hline 13 & \multirow{2}{*}{$\begin{array}{l}\text { Danfeng } \\
\text { Street }\end{array}$} & \multirow{2}{*}{ Type 7} & Peak & 39 & 0.7829 & $17.14 \%$ \\
\hline 14 & & & Non-peak & 41 & 0.7614 & $16.14 \%$ \\
\hline
\end{tabular}

To fully evaluate the performance of the proposed method, the values of MAPE and linear regression analysis between calculated and observed bus dwell time and time lost serving stop were graphed, as shown in Figure 8. Scattered data points of peak and non-peak periods were balanced on both sides of the lines of identity, which indicated that the proposed model was not overvalued or undervalued. R-square and MAPE were calculated to be 0.8840 and $13.20 \%$ for non-peak and 0.8387 and $13.46 \%$ for peak, indicating that the proposed method could estimate bus dwell time and time lost serving stop relatively accurately. 
FIGURE 8.

Fitted relationships of bus dwell time and time lost serving stop between calculated and observed data

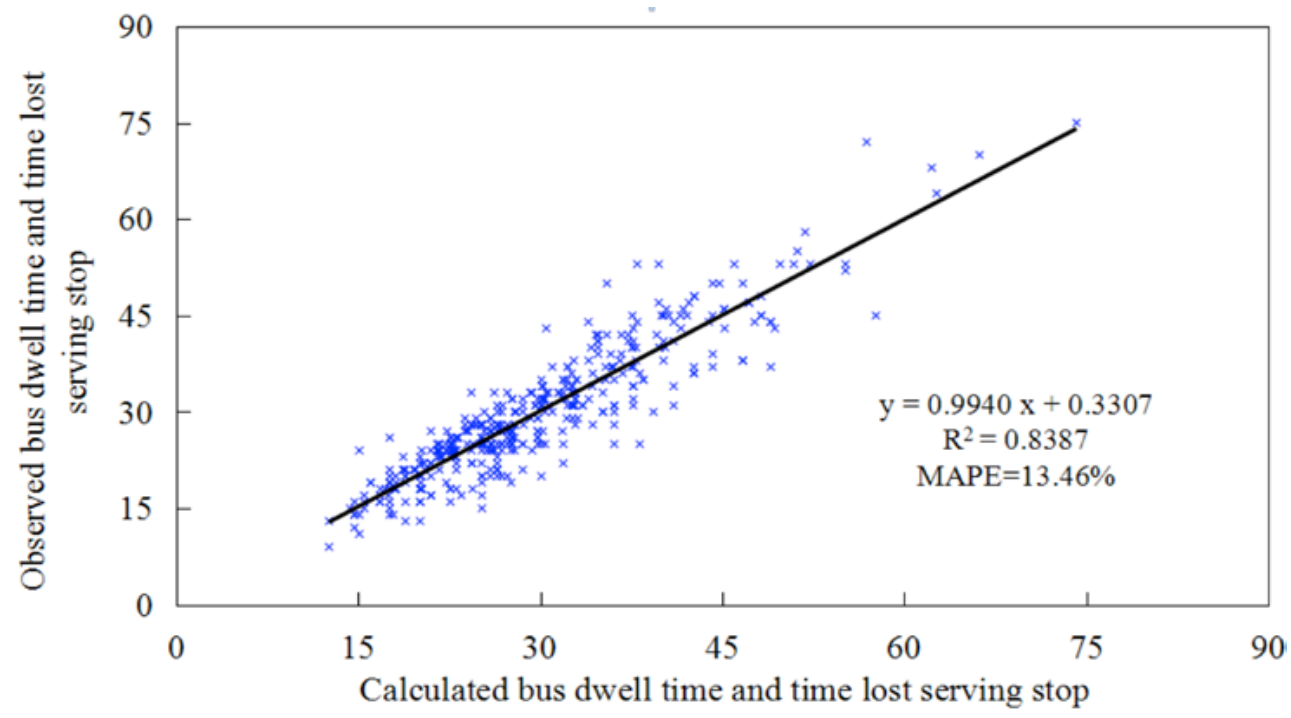

(a) Peak period

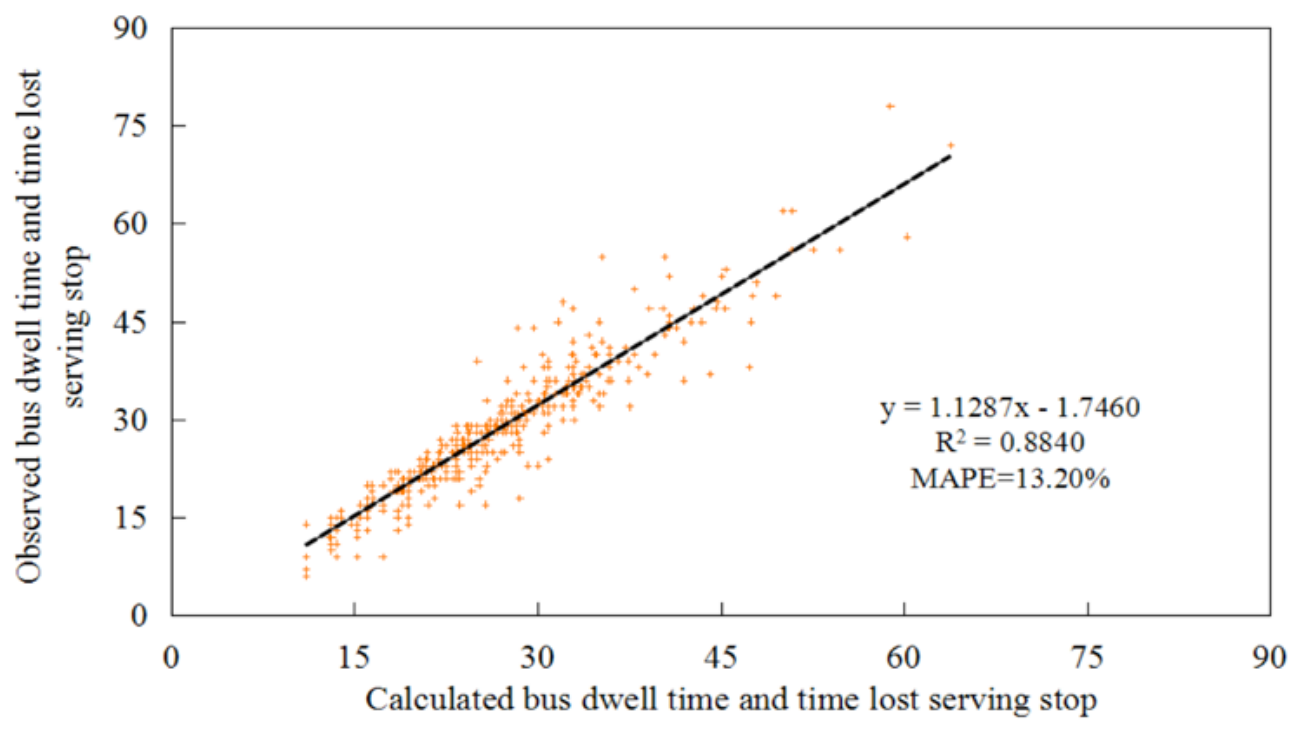

(b) Non-peak period

\section{Sensitivity Analysis}

Bus stop locations could significantly impact the delay of a bus at a bus stop. In light of this, a sensitivity analysis was conducted to investigate the effects of bus stop locations on bus dwell time and time lost serving stop. As shown in Figure 9, bus stop locations are of three types: near-side, far-side, and mid-block. In this study, Type 3 (Public Transport Corporation) and Type 6 (Gangding) were near-side stops; Type 1 (Gulou North), Type 5 (Renmin Park), and Type 7 (Danfeng Street) were far-side stops; and Type 2 (Beiji Huitang) and Type 4 (Xuanwuhu Park) were mid-block stops. 
FIGURE 9.

Schematic drawing of bus stop locations

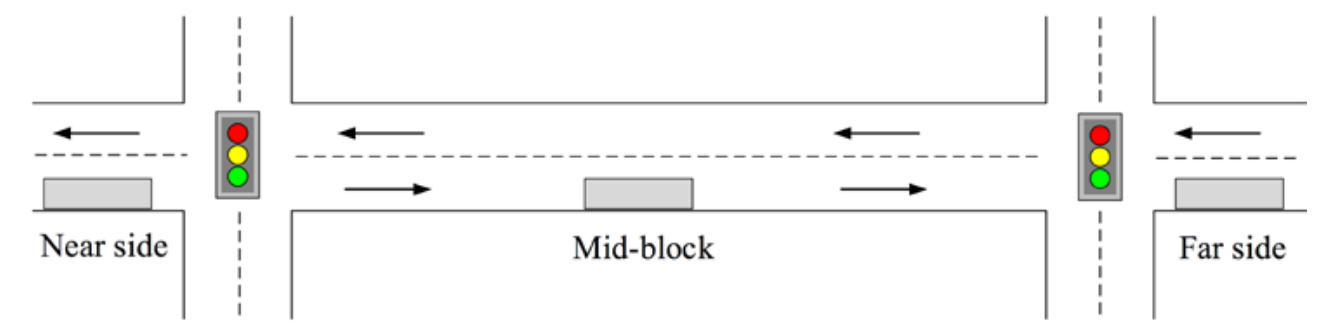

Analytical results of bus dwell time and time lost serving stop including maximum value, minimum value, mean value, median value, and standard variation are summarized in Table 5. Bus dwell time and time lost serving stop were analyzed based on different bus stop locations (near-side, far-side, and mid-block) and time periods (peak and non-peak). As can be seen, the mean and median values at near-side stops were higher than those at far-side and mid-block stops, indicating that near-side stops had a significant impact on bus dwell time and time lost serving stop. A near-side bus stop is located immediately prior to an intersection and may be influenced by other vehicles in the intersection. Compared with far-side and mid-block bus stops, a near-side bus stop has longer average delay for re-entering the traffic stream, bus stop failure time, and traffic signal delay. For instance, at a near-side bus stop, a bus must wait at the stop until all of the buses have finished serving their passengers and have a green signal enabling them to proceed down the street. Thus, a near-side bus stop creates longer bus dwell time and time lost serving stop. In addition, the mean and median values of near-side, far-side and mid-block stops during the peak period were more than those during the non-peak period.

TABLE 5.

Bus Dwell Time and Time Lost Serving Stop at Different Stop

\begin{tabular}{|c|c|c|c|c|c|c|c|}
\hline $\begin{array}{c}\text { Bus Stop } \\
\text { Location }\end{array}$ & State & $\begin{array}{c}\text { Sample } \\
\text { Size }\end{array}$ & $\operatorname{Max}(\mathbf{s})$ & Min (s) & Mean (s) & Median (s) & SD (s) \\
\hline \multirow{2}{*}{ Near-side stop } & Peak & 147 & 69.00 & 19.00 & 33.74 & 32.00 & 9.16 \\
\cline { 2 - 8 } & Non-peak & 153 & 59.00 & 12.00 & 30.43 & 29.00 & 8.44 \\
\hline \multirow{2}{*}{ Far-side stop } & Peak & 140 & 73.00 & 13.00 & 28.22 & 27.00 & 9.19 \\
\cline { 2 - 8 } & Non-peak & 128 & 60.00 & 10.00 & 28.06 & 26.00 & 8.06 \\
\hline \multirow{2}{*}{ Mid-block stop } & Peak & 153 & 73.00 & 10.00 & 27.52 & 25.00 & 11.21 \\
\cline { 2 - 8 } & Non-peak & 164 & 75.00 & 9.00 & 27.01 & 22.00 & 13.68 \\
\hline
\end{tabular}

Frequency histogram and cumulative distribution curves for bus dwell time and time lost serving stop at different bus stop locations are presented in Figure 10. For the peak period, cumulative curves for dwell time and time lost serving stop at near-side stops were below the curves for far-side and mid-block stops, indicating bus stop location could have an influence on dwell time and time lost serving stop.

T-tests were further conducted to compare bus dwell time and time lost serving stop at near-side, far-side, and mid-block stops. Results showed that the differences in bus dwell time and time lost serving stop taken at near-side and far-side stops and near-side and mid-block stops during peak and non-peak periods were all statistically significant. However, the differences taken at far-side and mid-block stops were not statistically significant. The findings further indicated that near-side stops could result in longer dwell time and time lost serving stop than the other two types of bus stops. 


\section{Conclusions}

This study proposed a method to estimate bus dwell time and time lost serving stop, which consists of deceleration time, time for serving boarding and alighting passengers, dead time, and acceleration time at the bus stop. A polynomial model incorporating kinematics of a particle was derived for estimating bus acceleration and deceleration times. In addition, descriptive statistics were used to analyze dead time, which involved average delay for re-entering the traffic stream, boarding lost time, bus stop failure time, and traffic signal delay.

A case study was conducted to show the applicability of the proposed model with data collected from the seven common types of bus stops in the cities of Nanjing, Changzhou, and Guangzhou, China. To validate the proposed method, a linear regression analysis was performed to find the correlation between calculated and observed bus dwell time and time lost serving stop. The results of R-square and MAPE ( 0.8840 and $13.20 \%$ for non-peak, 0.8387 and $13.46 \%$ for peak) indicated that the proposed method was well validated and could be practically used in China for the analysis and estimation of bus dwell time and time lost serving stop. In addition, sensitivity analyses were conducted to investigate the effects of bus stop locations on bus dwell time and time lost serving stop. The results showed that the differences taken at near-side and far-side stops and near-side and mid-block stops during peak and nonpeak periods were all statistically significant. However, the differences taken at far-side and mid-block stops were not statistically significant. The findings further indicated that near-side stops could result in longer dwell time and time lost serving stop than the other two types of bus stops.

This study explored the bus dwell time and time lost serving stop in urban locations for general weather conditions. Different weather conditions (such as inclement weather conditions) and different locations (such as suburban locations) may have impacts on the performance of the proposed method. Further research can be conducted to investigate their impacts.

In addition, the proposed method can be applied in other locations; however, in different countries, especially in other developing countries, the service time for each passenger and bus dead time at a stop may be different. Thus, to apply the proposed method in other countries, the transit agency will need to collect traffic data to obtain the corresponding characteristics, such as the service time for each passenger. 


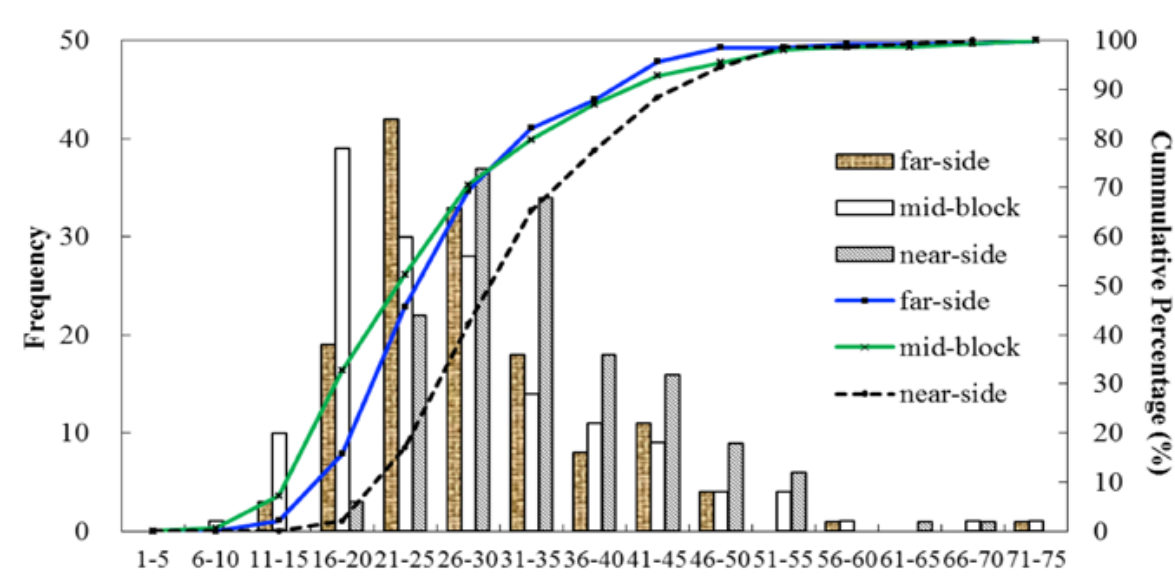

(a) Peak

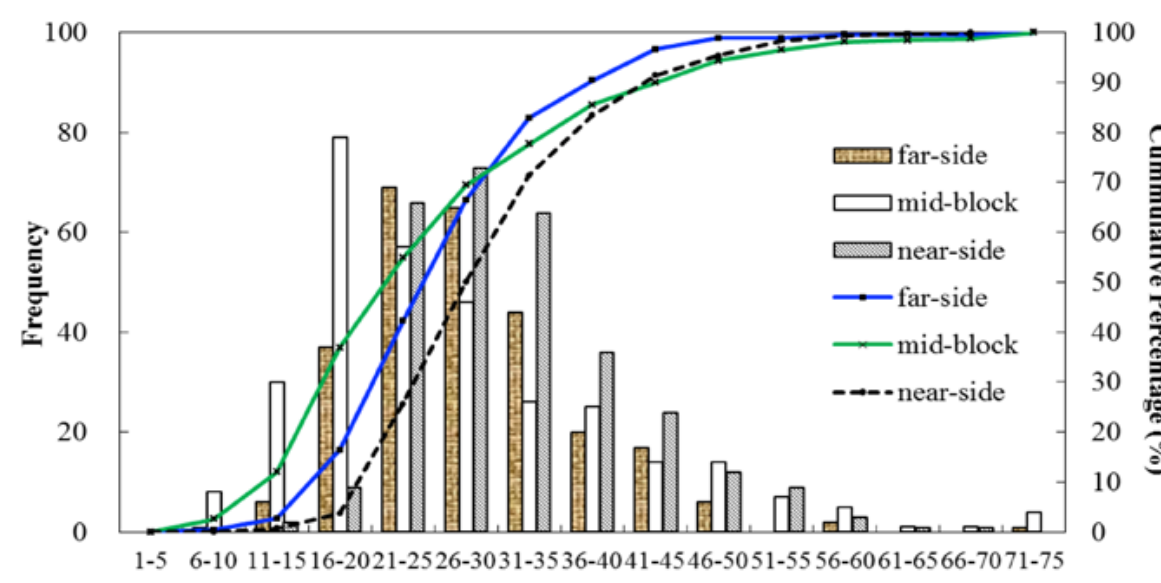

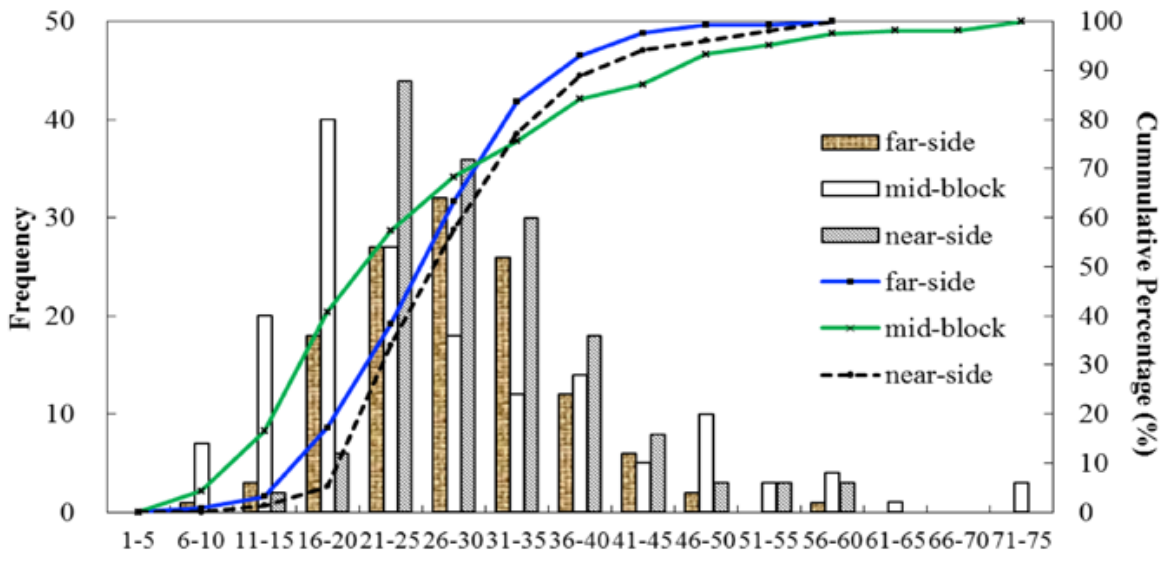

(b) Non-peak

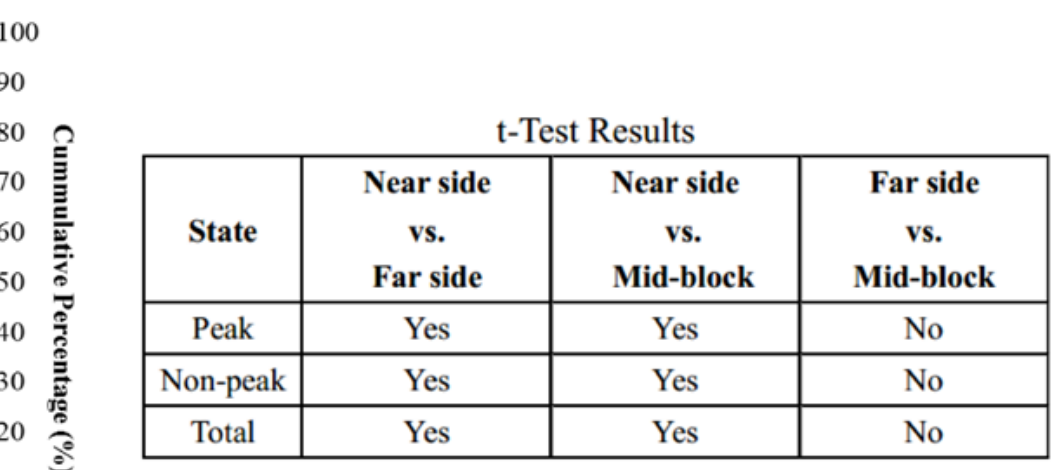

(c) Total

FIGURE 10. Comparison between bus dwell time and time lost serving stop at near-side, far-side and mid-block stops 


\section{Acknowledgments}

This study was sponsored by the National Science Foundation of China (No. 51308114), the Scientific Research Foundation for the Returned Overseas Chinese Scholars of State Education Ministry, the Key Project of National Science Foundation of China (No. 51338003), and the Scientific Research Foundation of the Graduate School of Southeast University (No.YBJJ1633).

\section{References}

Balasubramanian, P., and K. Rao. 2015. "An Adaptive Long-Term Bus Arrival Time Prediction Model with Cyclic Variations." Journal of Public Transportation, 18(1): 1-18.

Bian, B., N. Zhu, S. Ling, and S. Ma. 2015. "Bus Service Time Estimation Model for a Curbside Bus Stop." Transportation Research Part C, 57: 103-121.

Ceder, A. 2007. Public Transit Planning and Operation: Theory, Modeling, and Practice. Butterworth-Heinemann, Oxford, UK.

Cundill, M., and P. Watts. 1973. "Bus Boarding and Alighting Times." TRRL Report LR 521. Transport and Road Research Laboratory, Wokingham, United Kingdom.

Dueker, K. J., T. J. Kimpel, and J. G. Strathman. 2004. "Determinants of Bus Dwell Time." Journal of Public Transportation, 7(1): 21-40.

Federal Highway Administration. 2003. "TSIS/CORSIM User's Manual, Version 5.1." Washington, DC.

Fernandez, R. 2010. "Modelling Public Transport Stops by Microscopic Simulation." Transportation Research Part C, 18(6): 856-868.

Fernandez, R., J. Gibson, and M. Mendez. 1995. "Modelacion del Comportamiento en Paraderos Formales." Actas del VII Congreso Chileno de Ingenieria de Transporte, Santiago, Oct. 17-20, 358-368.

Fitzpatrick, K., K. Hall, D. Perkinson, L. Nowlin, and R. Koppa. 1996. "Guidelines for the Location and Design of Bus Stop." TCRP Report 19. Transportation Research Board, Washington, DC.

Furth, P., and T. Muller. 2007. "Part 4: Capacity and Quality of Service-Service Reliability and Hidden Waiting Time: Insights from Automatic Vehicle Location Data." Transportation Research Record, 1955: 79-87.

Gu, W., Y. Li, M. J. Cassidy, and J. B. Griswold. 2011. "On the Capacity of Isolated, Curbside Bus Stops." Transportation Research Part B, 45: 714-723.

Guenthner, R., and K. Hamat. 1988. "Transit Dwell Time under Complex Fare Structure." Journal of Transportation Engineering, 114(3): 367-379.

Hadas, Y., and A. Ceder. 2010. “Optimal Coordination of Public-transit Vehicles Using Operational Tactics Examined by Simulation." Transportation Research Part C, 19: 879-895. 
Hamdouch, Y., H. W. Ho, A. Sumalee, and G. Wang. 2011. "Schedule-based Transit Assignment Model with Vehicle Capacity and Seat Availability." Transportation Research Part B, 45(10): 1805-1830.

Hawas, Y. E. 2013. "Simulation-based Regression Models to Estimate Bus Routes and Network Travel Times." Journal of Public Transportation, 16(4): 107-130.

Jacques, K. S., and H. S. Levinson. 1997. "Operational Analysis of Bus Lanes on Arterials." TCRP Report 26. Transportation Research Board, Washington, DC.

Jaiswal, S. 2010. "Busway Platform Bus Capacity Analysis." Ph.D. thesis. Queensland University of Technology, Brisbane, Australia.

Jaiswal, S., J. Bunker, and L. Ferreira. 2010. "Influence of Platform Walking on BRT Station Bus Dwell Time Estimation: Australian Analysis." Journal of Transportation Engineering, 136: 1173-1179.

KFH Group. 2013. Transit Capacity and Quality of Service Manual, Third Edition. Transportation Research Board, Washington, DC.

Leurent, F., E. Chandakas, and A. Poulhès. 2014. "A Traffic Assignment Model for Passenger Transit on a Capacitated Network: Bi-layer Framework, Line Sub-Models and Large-Scale Application." Transportation Research Part C, 47: 3-27.

Levine, J., and G. Torng. 1994. “Dwell Time Effects of Low Floor Bus Design.” Journal of Transportation Engineering, 120(6): 914-929.

Levinson, H. S. 1983. "Analyzing Transit Travel Time Performance." Transportation Research Record, 915: 1-6.

Li, M., F. Zhao, L. Chow, H. Zhang, and S. Li. 2006. "Simulation Model for Estimating Bus Dwell Time by Simultaneously Considering Numbers of Disembarking and Boarding Passengers." Transportation Research Record, 1971: 59-65.

Lin, T., and N. H. M. Wilson. 1992. "Dwell Time Relationships for Light Rail Systems." Transportation Research Record, 1361: 287-295.

Meng, Q., and X. Qu. 2013. “Bus Dwell Time Estimation at Bus Bays: A Probabilistic Approach.” Transportation Research Part C, 36: 61-71.

Milkovits, M. N. 2008. "Modeling the Factors Affecting Bus Stop Dwell Time: Use of Automatic Passenger Counting, Automatic Fare Counting, and Automatic Vehicle Location Data." Transportation Research Record, 2072: 125-130.

PTV Group. 2005. VISSIM User Manual, Version 4.10. Karlsruhe, Germany.

Robinson, S. 2013. "Measuring Bus Stop Dwell Time and Time Lost Serving Stop with London iBus Automatic Vehicle Location Data." Transportation Research Record, 2352: 68-75.

Szeto, W. Y., M. Solayappan, and Y. Jiang. 2011. "Reliability-based Transit Assignment for Congested Stochastic Transit Networks." Computer-Aided Civil and Infrastructure Engineering, 26: 311-326. 
Tirachini, A. 2013. "Bus Dwell Time: The Effect of Different Fare Collection Systems, Bus Floor Level and Age of Passengers." Transportmetrica A, 9(1): 28-49.

Transportation Research Board. 2000. Highway Capacity Manual. Washington, DC.

Wu, Y., J. Tang, Y. Yu, and Z. Pan. 2015. "A Stochastic Optimization Model for Transit Network Timetable Design to Mitigate the Randomness of Traveling Time by Adding Slack Time." Transportation Research Part C, 52: 15-31.

Yan, Y., Z. Liu, Q. Meng, and Y. Jiang. 2013. "Robust Optimization Model of Bus Transit Network Design with Stochastic Travel Time." Journal of Transportation Engineering, 139(6): 625-634.

Yang, X., Z. Gao, X. Zhao, and B. Si. 2009. "Road Capacity at Bus Stops with Mixed Traffic Flow in China." Transportation Research Record, 2111: 18-23.

Ye, Z., C. Wang, Y. Yu, X. Shi, and W. Wang. 2016. "Modeling Level-of-Safety for Bus Stops in China." Traffic Injury Prevention, DOI: 10.1080/15389588.2015.1133905.

\section{About the Authors}

Chao Wang (woashiachaoazia@163.com) is currently a Ph.D. candidate in the School of Transportation, Southeast University. He received his B.E. degree in traffic engineering from Shandong University of Technology, China in 2013. His research interests include public transportation, traffic system modeling and traffic safety.

ZHIRUI YE (yezhirui@seu.edu.cn) earned his Ph.D. degree in Transportation Engineering from Texas A\&M University. He has more than 10 years of experience in transportation engineering and science research and is a professor in the School of Transportation and director of the Institute of Transportation Engineering at Southeast University, China. Previously, he was a research scientist at the Western Transportation Institute at Montana State University.

YUAN WANG (wangyuan_1990@seu.edu.cn) received her B.S. in transportation engineering from Southeast University in 2012. She is now a Ph.D. candidate in transportation engineering at Southeast University. Her research interests include public transportation and traffic safety.

YUERU XU (xuyr1992@163.com) received his B.S. in transportation engineering from Southeast University in 2013. He is now a graduate research assistant in transportation engineering at Southeast University. His research interests include public transportation and traffic safety.

WEI WANG (wangwei@seu.edu.cn) is a professor in the School of Transportation at Southeast University. During the past decades, he has focused on teaching and conducting research in the areas of transportation system planning and management, traffic flow theory, highway capacity, and intelligent transportation systems. 